\title{
Agents of change: temporal flow and feeling oneself act
}

\author{
Nick Young ${ }^{1}$
}

Accepted: 11 January 2022 / Published online: 25 February 2022

(c) The Author(s) 2022

\begin{abstract}
Here, I put forward a new account of how experience gives rise to the belief that time passes. While there is considerable disagreement amongst metaphysicians as to whether time really does pass, it has struck many as a default, 'common sense' way of thinking about the world. A popular way of explaining how such a belief arises is to say that it seems perceptually as though time passes. Here I outline some difficulties for this approach, and propose instead that the belief in time passing is elicited by a particular feature of agentive experience. When we deliberately move our bodies, bring something to mind, or focus our attention, we experience ourselves as the sources of these actions. Sensing oneself as a source, I argue, is a unique type of change experience, one which leads us to a belief that time is passing.
\end{abstract}

\section{Introduction}

My aim here is to show how experience leads to the belief that time passes. The novelty of the account I propose lies in the type of experience which causes this belief. While it is often supposed that some aspect of perceptual experience leads to a belief in temporal passage, I argue here that a particular feature of agentive experience is in fact responsible.

The structure of this paper is as follows. Section 2 outlines what I mean by the common sense belief that time passes, and the general contours of experience-based explanations as to how such a belief arises. In Sect. 3 I argue that attempts to show how the belief in temporal passage is based on perceptual experiences of change face difficulties, giving us reason to consider the possibility that some other, non-percep-

Nick Young

nickyoung1@gmail.com

1 Department of Philosophy, Università degli Studi di Milano, Via Festa del Perdono, 7, 20122 Milano, Italy 
tual, type of experience is responsible instead. Section 4 focuses on a related common sense belief about time -the idea that there is a privileged present moment- and summarises a recent suggestion by Hoerl as to how the structure of perceptual experience can be thought of as inviting this type of belief. In Sect. 5, I outline a feature of our agentive phenomenology, which Horgan calls the "what-it's-like of self as source" (2011, p. 79), which I argue in Sect. 6 can be thought of as a unique type of change experience. In Sect. 7, I suggest that this agentive experience of change invites the belief that time passes.

\section{Believing in the passing of time}

Torrengo (2017) defines "the feeling of the passing of time"as:

whatever ingredient of our experience tells us that time passes (that is, the ingredient on which the common-sense belief that time passes is based)" (p. 4).

Various candidates as to what this experiential ingredient is have been put forward in recent years. Often, such proposals identify some feature or other of perception as responsible for a belief in temporal passage. Here, I am going to argue that a particular aspect of agentive experience makes for a better option. Before getting to the nitty gritty of my argument, I will first outline in general terms how experienced-based explanations of our belief in passage are supposed to work, along with some of their underlying assumptions.

First, the strategy relies on the idea that there is such a thing as "the common-sense belief that time passes". Is there such a thing? If there is, what does it amount to? At the core of traditional philosophical conceptions of temporal passage is the idea of a changing present moment. While standard passage realist views of time, such as the growing block (e.g. Correia \& Rosenkranz 2018), the moving spotlight (e.g. Cameron 2015), and presentism (e.g. Ingram 2018), differ as to the metaphysical status ascribed to the past or future, each has some sort of marker between the past and the future (the edge of the block, the spotlight, the present moment itself), and this marker is perpetually in flux. Passage anti-realists, on the other hand, deny that there is a changing present dividing the present from the past: time is a 'static block', not a growing one. Typically, the denial that there is a changing present is understood as a denial that time passes; however, some have defended more minimal conceptions of temporal passage which do not appeal to a changing present (e.g. Deng 2013; Leininger 2013; Mozersky 2015.). On this type of view, passage is real, but it is not robust. According to Deng, for example, temporal passage consists in there being simply a "succession of times" (2013, p. 2020).

For present purposes, what we should believe about the passing of time -whether it is real, whether it involves a changing present- is less important than the question of whether such ideas are part of the folk conception of time. It is common for both passage realists and anti-realists to describe the idea that time passes as common sense: as something that those with no interest in philosophy or theoretical physics, would take to be true. It is certainly true that people frequently talk about time pass- 
ing, but should we take this to mean that they think of time in terms of a changing present moment? In fact, there is some reason to doubt that such an idea is quite as widespread as is sometimes assumed. A recent study by Latham et al. (2021) presented 600 U.S. residents with six descriptions of the universe, three describing time in passage realist terms (the growing block, the moving spotlight, and presentism), and three in anti-realist terms (B-theory, C-theory, and Quantum Gravity). ${ }^{1}$ When asked "Which of these universes is most like our universe?" approximately $70 \%$ of participants chose a passage-realist description, but around 30\% chose an antirealist description. Given that this is only one study, made up from residents of only one country, we should be wary of over-generalising its findings; however, it shows that a belief in robust temporal passage is not a universally held belief. We might say that a belief in robust passage is common, but not common enough to count as common-sense.

Despite these complications, my focus here will be on how experience might lead one to believe that time passes in a robust, changing-present sense. Even if belief in a changing present is less common than we might have thought, it is still worthwhile to investigate how it arises. Why does it strike some (presumably significant) portion of the population as correct? Why has it struck many philosophers as the most obvious way of thinking about time? Indeed, a better understanding of why some people believe that time passes, might well shed light on why others do not believe that it does.

We can understand 'experience' to mean those mental states which have some type of phenomenological character. Experience-based approaches attempt to show that some representational, structural, or phenomenological feature, of some type of experiential state, causes the belief that time passes. Accounts differ as to which aspect, of which type, of experience they pick out, and the story they tell as to how this aspect leads to a belief in passage. Although Torrengo suggests that the feeling of passage is "whatever" ingredient of experience achieves this, it is very common to identify it with an experience of, or closely connected to, change. This is understandable: if we are trying to explain how a belief about change arises, experiences of change, or changing experiences, seem like an obvious place to start. ${ }^{2}$ Potential candidates as to the type of change experience that is doing the work include: "the sensation of a flowing time and a moving present moment" (Davies 1995, p. 275), perceptual representations of ordinary sorts of change such as colours fading or clock hands moving (e.g. Dainton 2012; Paul 2010; Prosser 2016), our "temporally evolving view" of the world (Miller et al. 2020, drawing on Ismael 2012) and Bayesian perceptual inference (Hohwy 2015).

Explanations differ as to how directly these sorts of experiences cause us to believe in a changing present. It might be, for example, a straightforward matter of our form-

\footnotetext{
${ }^{1}$ Neither this study nor other recent inquiries into our folk beliefs about time (Shardlow et al. 2021; Latham et al. 2020) examine participants' intuitions regarding the minimal conception of passage mentioned in the previous paragraph. It is therefore an open question as to how common it is for non-philosophers to understand time in this way.

${ }^{2}$ Torrengo himself is an exception here. On his phenomenal modifier view the feeling of passage is not essentially linked to experiences of change, but is instead a structural feature possessed by many different types of experience.
} 
ing the belief that time passes because we experience it as passing (analogous to our believing there is an ice cream before us because we see an ice before us), alternatively, it is sometimes suggested that our belief in a dynamic, changing present, is due to experiences of change having a dynamic phenomenal character. Miller et al. (2020) argue that the route between experience and belief in passage is more circuitous. On their account, our having a temporally evolving view of the world leads to the development of what they call "passage-friendly language", which not only causes us to believe that time passes, but also that our temporally evolving view is an experience of time passing.

In this paper I will put forward a new experience-based approach: our agentive experience of ourselves as effecting change in the world leads us to believe that there is a changing present. I will not argue that agentive experience involves a representation as of time passing, nor that it possesses some sort of intrinsically dynamic phenomenology (in the next section we shall see some reasons for rejecting both of these ideas). Neither will I rely on the idea that experience causes belief in passage only via the development of passage-friendly language. Instead, I will present a different type of indirect explanation: our experience of ourselves as acting does not provide an explanation as to why we must act, and this, I will argue, invites the belief that there is a changing present moment. ${ }^{3}$

\section{Perceiving change as experiencing passage}

The most obvious way in which experience tells us anything is through our perceiving features of the world. Visual experience tells us that there is a tree before us insomuch as we visually represent an object with a certain colour, shape etc. Perception also tells us about change: we can see the droplet of ice cream rolling down the cone. ${ }^{4}$ Given that we are trying to explain a belief in a type of change, and perception tells us about change, an obvious move to make is to say that we believe the present to be changing because we perceive it to be changing. However, it is implausible to think that we perceive the present moment changing in exactly the same way that we see an ice cream dripping. Material objects are the sort of things that we can perceive to change, and we perceive these things as changing through time: part of seeing a droplet move is to see it as occupying different locations at different moments. 'Now' is not an object we can perceive (nor a sound, odour, or anything else we would ordinarily think of as a perceptual object), and is itself a moment of time: an experience of time passing cannot be any ordinary sort of change perception.

\footnotetext{
${ }^{3}$ I will not argue here that my proposal is superior to that of Miller et al. Indeed, it might be possible to 'mix and match' the components of my view with the components of theirs. That is, agentive experience could contribute to the development of passage friendly language, and so cause a belief in passage this way. Alternatively, the account I offer here as to how experience invites belief could be used to explain how Ismael's temporally evolving point of view leads to a belief in passage without the need for passagefriendly language.

${ }^{4}$ There are a variety of views as to what change perception involves (e.g. Arstila 2018; Lee 2014; Phillips 2014).
} 
Could it be instead some extraordinary type of perception? While we do not see, hear, smell etc. the present as changing in any normal sense perhaps we still form some sort of perceptual representation, the content of which is 'the present is changing'? This approach is not normally thought to be especially plausible either. Prosser, for example, has argued against the idea that, given causal and counterfactual constraints on perception, the passage of time is not something that could be perceived even if time really did pass (2013). The idea that we misperceive time as passing, that the experience of passage is an illusion, is also problematic. We tend to think of illusions as perceptions of a way the world could be, but is not. Take the well worn example of a stick looking bent in water: the subject visually represents a way the world could be (the stick could actually be bent), which does not match up with how the world actually is. But if there is no such thing as time passing, if it is not a way the world could be, then there is no contrast case with which to make sense of what it would be to misrepresent the world as being this way. ${ }^{5}$

A different approach, popular amongst passage anti-realists, is to argue that perception tells us that time is passing, not by representing the present as changing, but through perceptions of ordinary change and movement exhibiting what we might think of as intrinsically dynamic phenomenology. According to this type of account, perceiving an object to change does not just involve our perceptual systems representing that object to have different properties, or be at different locations, at different moments, but also adding on what Dainton calls a "distinctively dynamic sensible appearance" (2012, p.127) or, as Paul puts it, representing that object in "some suitably animated or flowing way" (2010, p. 352). Not realising that this dynamic quality is something produced by our own minds, we mistakenly come to believe that this feature belongs to the world, and so come to believe that we are experiencing time passing. The idea that this quality is something that the perceptual system adds to our perceptions of the world is justified by an appeal to a phenomenon known as the phi illusion (Kolers \& von Grünaun 1976): subjects presented with two dots in quick succession and in slightly different locations do not have an experience of one dot followed by another, but of a single dot moving continuously through space. ${ }^{6}$ The fact that two static inputs can give rise to a perception of a single 'animated' object is taken as evidence that this dynamic quality is a product of the perceptual system. The final step is to say that what occurs in the phi case also occurs when we perceive real change or movement. According to the passage anti-realist the world consists of nothing but static inputs, all there is to an object moving is for it to occupy different positions at different times. However, as with the phi case, if objects are at different positions within a short enough time frame, our perceptual system presents them as having a dynamic appearance.

One way of challenging this type of approach is to argue that, in fact, there is no good reason to think that the perceptual system really does add any extra property to perception of change (Hoerl 2014). While I find this line of thought persuasive, I

\footnotetext{
${ }^{5}$ See Hoerl (2014) for more details on this type of worry.

${ }^{6}$ Although phi and related phenomena have been described many times in the philosophical and psychological literature on temporal perception, I repeat these details here as they shall be important for arguments I make later in this section.
} 
want to argue here that even if we grant that our experiences of moving or changing objects are augmented in the manner just outlined, perceiving ordinary change cannot be the experiential ingredient that tells us time is passing.

First, it is unclear how a phenomenological feature can be dynamic in and of itself. Even if experiences of moving or changing objects possess some feature that experience of unmoving or unchanging objects lack, it is not obvious what makes this extra quality dynamic in such a way that it leads to a belief in temporal passage. On a standard representationalist view of perception, phenomenological features either supervene on, or are identical to representational content (Chalmers 2004; Crane 2009). The distinctive experiential quality that we enjoy when looking at a ripe tomato or a fire engine either supervenes on or is identical to the perceptual content 'is red'. However, it does not seem as though we can say very much more than this about the character of phenomenal properties. The quality red does not seem to be 'distinctively' or 'suitably' anything other than...red. While we might have associations with phenomenological redness (rage, danger. passion), the quality, in and of itself does not seem to be telling us anything more about the world than the presence of red. Similarly, while we might, for obvious reasons, associate the phenomenal character of changing objects with dynamism or animation, it is hard to see why such a quality would be dynamic, or suggestive of temporal passage, in any stronger sense. ${ }^{7}$

Third, there is the question of what to say when, as it were, the music stops. We can have perceptual experiences of nothing moving or changing at all -imagine sitting stock still, staring straight ahead, hearing only the steady hum of your central heating. Time does not seem to grind to a halt in these sorts of situations. ${ }^{8}$ I want to be careful here and distinguish the suggestion I am making from a stronger one. It is sometimes suggested (for example Torrengo 2017, p.12) that all types of conscious state come with a sense of time passing. I think this is too strong, or at least requires some further argument to prove that it is so. We also often speak of situations in which we 'lose track of time', such as when we are thoroughly engaged in some activity like playing a sport or a musical instrument (e.g. what in psychology is referred to as a flow state) or when we are lost in thought. ${ }^{9}$ The challenge for accounts based on change perception is to explain why we can, at least sometimes, experience the feeling of the passing of time when there is no change around to be perceived.

One response to this type of difficulty can be found in the following remarks of Prosser:

While it is tempting to think that in the complete absence of sensory experience it could still seem to one that time was passing, it is not clear that one would ever be free from awareness of something - one's own thoughts, if nothing

\footnotetext{
${ }^{7}$ Farr makes somewhat similar objections to intrinsically dynamic qualia in his 2020.

${ }^{8}$ O'Shaughnessy says: "Even in the situation of total lack of change in the objects of perception, change continues- within. However frozen the perceptible world may in fact be, the internal clock of consciousness ticks on." (2000, p. 61). Borges' short-story The Secret Miracle (1962) provides a vivid description of what an extreme form of this type of experience might be like.

${ }^{9}$ I will return to moments in which we lose track of time in Sects. 6 and 7.
} 
else. For example I assume one would generally have an ever-changing sense of how long one had been in sensory deprivation $(2016, \text { p. 180 })^{10}$

The idea here seems to be that we never experience true stillness, because even when we are not perceiving change, we continue to experience changes in our mental life. However, this seems to require two commitments which we might be reluctant to endorse. First, it seems we must say that, unlike perceptual experience, conscious thought, or some other experientially apparent aspect of our inner mental life, is always changing. But this is, at least, not obviously true. Paul, for example, seems to think that we can experience unchanging thoughts:

if we were in an entirely static environment where there were no contrasts between property instances (this would have to include no contrasts with respect to properties of my thoughts), then it would seem to us as though time were standing still. And, indeed, I think this is a very plausible supposition. (Paul 2010, p. 355, emphasis mine)

Intuitions might go either way here, but in the absence of an argument one way or the other, we might doubt whether Prosser's suggestion is on firm foundations.

Second, even if we grant that our inner lives are ever-changing, for this to explain why our experience of passage continues when the perceptual world stands still, introspective awareness of these changes would need to be very similar to perceptual experiences of change, and this should certainly give us reason for pause. As we have seen, according to views which rely on intrinsically dynamic phenomenology, when an object is perceived as having contrasting properties in quick succession, it takes on an animated appearance, and this appearance is a product of the perceptual system. For changing thoughts to provide an experience of passage in the absence of perceived change, an inner analog of this perceptual augmentation would be required. That is, when a conscious thought has contrasting properties in quick succession the mind must add a dynamic appearance to it, just as it does when we perceive an object with contrasting properties. ${ }^{11}$ However, while there are accounts on which introspection is a form of 'inner sense' (e.g. Armstrong 2002, ch. 15; Nichols and Stitch 2003), even their proponents would say that there are significant differences

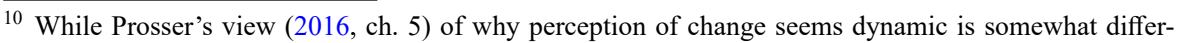
ent to Paul and Dainton's, I think the issues raised in this section apply to his account as much as theirs. Hoerl (2014) thinks that all three positions can be criticised in a broadly similar way. Prosser also makes clear that he thinks that experiences of change are only part of why time seems to pass (2016, p. 179), and suggests that "the sense of temporal motion" (p. 187) and the sense that the future seems "subjectively open" (p. 198) might also contribute. However, he does not consider the sense of temporal motion to be part of our "immediate phenomenology" but is "encountered when we think about the past and present" (p. 177-178), suggesting that does not contribute to it seeming, experientially, as if time passes. And, as I make clear when considering Callendar's (2017) view in Sect. 5, a sense of the future being open is not equivalent to an experience of passage.

${ }^{11}$ It might be objected here that we can be aware of our thoughts changing in some other way which is not so similar to perceiving change. However, for this sort of argument to be made to work, not only would we require an account of how we experience thoughts as changing, we would also have to show why this new sort of change experience also has a dynamic phenomenology suggestive of passage.
} 
between perception and introspection, and, other than saving the idea that dynamic phenomenology leads to a belief in passage, it does not seem as if we have any reason to think dynamic phenomenology is added to aspects of our inner life. Recall also that the idea of added dynamic phenomenology in perception is motivated by the phi illusion, but it is difficult to even make sense of what an inner analog to phi could be. Can we make sense of the idea that two thoughts with contrasting properties could be mistaken for a single changing thought? Moreover, the idea that thoughts are experienced as having a dynamic appearance which they do not in fact possess is in tension with the widely held view that introspective awareness provides infallible, or close to infallible, knowledge of the aspects of our minds that we have access to (e.g. Shoemaker 1994; Wright 2000). Even if we accept that perceptions of change possess an illusory element, it is much harder to make the analogous case for inner experience.

In this section we have seen that two of the most obvious ways of cashing out the idea that perceptual experience tells us that time passes face serious difficulties. While this is not meant to be a knock down argument against the idea that a belief in time passing could come from perception, it does give us a reason to consider whether other, non-perceptual, forms of experience might do a better job. There is more to sensuous first-person experience than perceiving, and there is no obvious reason to think that the experiential ingredient which tells us time passes must be perceptual, or, in the case of mental change, quasi-perceptual. The discussion so far has also given us reason to consider other interpretations of what it means for experience to tell us that time is passing. There is no reason to think that a 'direct' representation of the present changing, nor the idea that there can be inherently dynamic phenomenology, would fare any better if they were transposed to some other, non-perceptual form of experience.

In the remainder of this paper, I will put forward a new account of how we come to believe that the present changes. The next section outlines an argument recently put forward by Hoerl on how a certain structural feature of perceptual experience can be said to invite a belief in a privileged present moment. In Sects. 5, 6, and 7 I argue that agentive experience invites the belief that the present moment is changing.

\section{Experience as inviting belief}

Embedded in the belief that the present moment is changing is -obviously- a belief that there is a present moment. In this section I will outline a proposal put forward by Hoerl (2018a) as to how a certain structural feature of perceptual experience elicits this more simple belief. Doing so will serve two purposes. First, the account I put forward in the next section can be thought to compliment to Hoerl's: his aim is to explain how our belief in a privileged present moment is elicited by perceptual experience; my aim is to show how the belief that this moment changes is elicited by agentive experience. Second, Hoerl's argument as to how perceptual experience can be thought of as inviting a belief in the privileged present will serve as a model for how I propose agentive experiences elicit a belief in the changing present.

Hoerl's starting point is an intuition that he identifies a number of writers on time and experience as having (e.g. Balashov 2005) which he summarises as follows: 
"it appears somehow essential to the nature of perceptual experience that it is the seeming disclosure of things as they are in the present" (2018a, p. 128).

As in the case of temporal passage one might be attracted to a very straightforward way of fleshing out what this seeming amounts to: perhaps perceptual experience represents, or presents, its objects as present? ${ }^{12}$ Strikingly, Hoerl goes in precisely the opposite direction, arguing that a distinguishing characteristic of perceptual experience is that it does not present its objects as having any sort of tensed character and that it is in fact this "lack of temporal viewpointedness" (p. 130) which is the basis for our belief that what we perceive is occurring at some metaphysically privileged moment:

When we experience an event, we experience that event to the exclusion of others that happen earlier or later, but nothing in our experience signals that this is due to anything to do with us... there is a sense in which what we experience is just the bare occurrence of that event. Thus, the nature of our experience invites instead the thought that the fact that we experience this event and not the others must have a metaphysical explanation: for example, that it is just this present event that is real or in some other way metaphysically special, whereas past and future events are not (p. 146).

Why would a lack of tensed content invite the belief in a privileged present? Hoerl argues for this point by comparing temporal and spatial experience.

In visuo-spatial perception... part of what is manifest in the experience itself is how what a subject can see depends on where she is located: In so far as she can distinguish between the location of the objects seen and the location from which they are seen, she can also grasp the dependence of the visibility of those objects, and of the way they figure in her experience, on her own position. In this way, the character of her experience itself reveals to the subject the reason why she perceives the particular objects she does and not others, and that this is some fact about her (ibid.)

What objects we see and the way those objects look, depends upon the point in space from which we are looking at them. Moreover, this dependence is manifest in the experience: what we see reveals some fact about our own location in relation to those objects. Spatial experience, in and of itself, therefore provides an answer as to why these objects are being perceived in this way: you are seeing this ice cream, and viewing it in profile, because you are located here. By saying that we lack a temporal viewpoint Hoerl is saying that temporal experience lacks an equivalent feature: we do not experience whatever event we experience from another point in time (in the way we view objects from another point in space), but neither do we experience ourselves as being at the same point in time as the event. At any instant, we simply experience the "bare occurrence" (ibid., p.145) of some event, and temporal experience does not

${ }^{12}$ Something like this account is put forward by Kriegel (2015a). 
make manifest why we are perceiving this event rather than any other. Given that the reason why we are experiencing this event rather than that one does not seem to depend on anything to do with us, we are led to believe, Hoerl argues, that it depends on some fact about the world. That is, according to Hoerl, we arrive at our belief in the privileged present abductively: at any instant of experience we are invited to believe that the event we are experiencing is somehow metaphysically privileged.

Notice that this account of our belief in a privileged present could be extended so as to account for a belief that the present moment changes. At any instant we can reflect on how perceptual experience is, was, and will be, and realise that there have been other instants which have seemed, and will be instants which will seem, as if they are metaphysically special. An obvious way of explaining why this is so would be to say that what is present changes. There is nothing wrong with this style of explanation per se: it shows a clear route between a particular structural feature of perceptual experience and our belief in passage. On the other hand, if we want to preserve the idea that a belief in the changing present is derived from some sort of experience of change, we might want to continue searching. ${ }^{13}$ Not to do so would be tantamount to giving up on the idea that there is a distinct feeling of passage at all. The account I will now propose retains the idea that there is such a feeling, but argues that it is an agentive rather than a perceptual experience of change.

\section{Experiencing oneself as a source of action.}

Here is an example of an event which, in contrast to those that Hoerl focuses on, you would experience as having something 'to do with you'. Standing in the park, you move your head forward and take a lick of the ice cream you are holding. The licking event is experienced as to do with you for an obvious reason: you experience yourself as its cause.

A number of philosophers have argued that there is something it is like to act, a phenomenology of agency, which accompanies our deliberate bodily movements and other types of action besides. In his 2011 Horgan et al. identifies two closely connected features of felt agency. The first of these is the "what-it's-like of self as source":

You experience your arm, hand, and fingers as being moved by you yourselfrather than experiencing their motion either as fortuitously moving just as you want them to move, or passively experiencing them as being caused by your own mental states. You experience the bodily motion as generated by yourself (ibid., p. 79).

and the second, "core optionality":

${ }_{13}$ Indeed, Hoerl does not intend his approach to be an explanation of our belief in temporal passage
(2018b, p. 13). 
Normally when you do something, you experience yourself as freely performing the action, in the sense that it is up to you whether or not to perform it. You experience yourself not only as generating the action, and not only as generating it purposefully, but also as generating it in such a manner that you could have done otherwise (ibid., p. 80).

Similar ideas can be found elsewhere (e.g. Kriegel 2015b, ch. 2; Nida-Rümelin 2018; Strawson 2010), ${ }^{14}$ and I take what Horgan to be referring to here to be fairly intuitive: we experience ourselves as the instigators of our actions, and while it might well be possible that we can experience ourselves as acting for reasons, the experience of acting does not seem to be as of introspectively bearing witness to these sorts of mental states causing us to act. We also experience these actions as something it is within our power to stop and start at any time, even if it would be irrational to do so, such as if we were being threatened to do something at gunpoint (Horgan 2011, p.81). Both aspects are obviously missing in cases of involuntary movement such as when a tap on the knee causes one's leg to jerk. We can also note that both of these features are present throughout the performance of an action. Taking a lick of your ice cream is not ballistic: you do not initiate the action and then observe your head to move forwards and your tongue to stick out. Rather, you feel yourself to be the action's source, and feel as though you could abort your licking, at every instant that the bodily movement is occurring.

In the next two sections, I will argue that our sense of ourselves as the source of our actions is an experience of change, one which invites the belief that the present moment is changing. Before that, it is worth noting that some authors have suggested that our experience of ourselves as acting freely is responsible for another common sense belief about time: the idea that the future is open. In a short section of his 2017, Callender, referring to core optionality, says:

Part of what it is to be an agent is to have this sense of freedom, a sense that other future options are in some sense live... as the self "evolves" up its worldline, it not only passes through various events and feels time to be flowing; it feels it is part of a worldwide surge of ' actualization' of one path over others. The sense of passage is intimately connected with the sense that the past is settled and the future open. (p.260-261)

It is true that the sense of temporal passage and the sense of an open future are connected. The idea that the present is changing is not far off from the idea that we can contribute to how it changes, thereby affecting the future. However, it should be stressed that the two can come apart and should be dealt with separately. It is perfectly coherent to believe that time is passing, and that experience tells us that this is so, without believing that the trajectory of unfolding events can be altered; we might believe that the present moment is changing but that how it will change is inevitable. Callender himself makes clear that he considers a belief in passage and a belief in the

\footnotetext{
14 There might well be more to agentive experience than these two features. See Mylopoulos and Shepherd (2020) for an overview of other possibilities.
} 
open future to be separate components in our manifest image of time. Indeed, prior to this passage he sets out at length his own account of how the belief in passage arises, in which agentive experience does not figure at all. ${ }^{15,16}$ Finally, as we shall see in Sect. 7, the account I will put forward as to how a belief in the changing present arises rests on the idea that feeling oneself as a cause includes a certain sense of limitation.

\section{Effecting change and feeling passage}

In Sect. 3 we saw that attempts to show how perceptual experiences of change lead to a belief in passage face difficulties: it is hard to make sense of how the present moment can be perceptually represented as changing (either veridically or nonveridically), and accounts which rely on our perceptions of ordinary types of change have difficulty explaining why time continues to seem to pass when no change is perceived, as well as why the phenomenological character of changing objects should lead to a belief in passage in the first place. I want to suggest now that the sense of causing one's actions provides what perception cannot: a pervasive experience of change which is not vulnerable to questions as to how to make sense of its veridicality, does not rely on intrinsically dynamic phenomenology, and allows for the feeling of passage to persist, even when no object is being perceived as moving or changing.

Feeling oneself as the source of an action, can be thought of as a unique type of change experience. Compare what it is like to watch the droplet of ice cream run down the ice cream cone with what it is like to move your head forward to take a lick. In the first case you are experiencing the world to change, in the second you are experiencing yourself as changing the world. You are not simply witnessing your head to change its location, but sensing yourself to be the instigator of the change. This seems a reasonable interpretation of what Horgan is describing when he talks about feeling your active body "as being moved by you yourself” (2011, p. 79). Similarly, in consciously bringing some mental image to mind you experience yourself as changing your inner world, and in shifting your attention, as changing what is at the centre and what is at the periphery of awareness. Such experiences provide a particularly intimate experience of change: it is not change that is experienced as belonging to the world around you but something experienced 'from the inside', something fundamental to what it is like to experience oneself as an agent.

In a moment, I will argue that sensing oneself as effecting change makes a good candidate for the experiential ingredient which tells us the present moment is changing. Before that, however, we can note that this type of change experience is not vulnerable to the challenges faced by the perceptual accounts of the feeling of passage outlined in Sect. 3. It was mentioned there that given the causal or counterfactual constraints on perception it was difficult to see how perceiving the present moment

\footnotetext{
${ }^{15}$ Indeed, Callender is a deflationist about the feeling of the passing of time: "What we need to explain is why creatures like us take the apparent tripartite structure of reality to be updating, not why we actually sense this" (ibid. p.230).

16 Similarly, Ismael considers our sense of ourselves as making decisions about how to act as connected to the notion that the future is open (2012) but does not consider it to contribute to a feeling of time passing.
} 
as changing could be veridical, but neither did it seem as if we had the conceptual resources to make sense of it as an illusion. Our sense of ourselves as causing actions is a state of ourselves that we are aware of through introspection, which, as mentioned, is a faculty often supposed to provide privileged access to, or perhaps even infallible knowledge of, aspects of our own minds. This allows for the difficulties suffered by the direct perceptual account to be side-stepped. Whether or not we really are causes of our own actions in the way experience presents us as being can be left as an open question, the world and all our actions within it might be fully determined after all, but it is difficult to see how we could be mistaken that we experience ourselves as causes, in the same way that it is difficult to imagine how we might be mistaken that we are experiencing red or feeling pain.

Neither does the account I am putting forward here rely on a commitment to intrinsically dynamic phenomenology. I am not arguing that the experience of instigating change has an extra animated element laid on top of it; rather, as we shall see in the next section, experiencing oneself as effecting change provides an explanation as to how the belief in passage arises which is similar to Hoerl's explanation as to why we believe in a privileged present. However, we might wonder whether identifying our sense of ourselves as sources with the feeling of the passing of time is vulnerable to a version of a problem suffered by the accounts of Dainton and Paul outlined in Sect. 3. There, I argued that accounts based on change perception have a problem explaining why time does not seem to stop passing whenever we stop perceiving change. Similarly, we might ask, if the feeling of the passing of time is our sensing ourselves acting, why does time not seem to stop passing when we stop acting? Does it not seem as though time continues to pass even at those moments when we simply sit around and do nothing?

One response to this challenge would be to say that the sense of ourselves as causing change is an experiential constant. We feel ourselves as effecting change at every instant we are conscious. To make this type of argument, I suggest, is much easier than claiming that we always (perceptually or quasi-perceptually) witness change. While we typically think of actions in terms of pronounced bodily movements, not all movements are pronounced, and not all actions are bodily moments. First, the moments in which we are not purposefully controlling our bodies are less common than we might think. Even as you sit reading these words you are still purposefully keeping your body rigid enough for it not to slide out of your chair, and are moving your eyes in such a way as to facilitate reading, rather than letting them glaze over or drift around the page. We might think that these more subtle movements carry with them a faint, "recessive" (Bayne 2008, p. 184) sense of agency. Nida-Rümelin goes as far as saying that even actions such as dancing in an unplanned and spontaneous manner, or reacting quickly and unreflectively to a potential danger are still experienced as "actively brought about" by oneself (2018, p. 64). There are also mental actions to consider. The body could be entirely at rest and yet we can still deliberately deliberate on a problem, purposefully bring a memory to mind, or privately curse in inner speech. Consider also the experience of actively directing and maintaining one's attention: you can shift your focus from the ice cream that you are holding to the feeling of your feet on the ground, or effortfully maintain your attention on what 
your companion is saying, despite the noisy park's myriad distractions. ${ }^{17}$ There is no reason to doubt that experiences of self as source accompany these inner actions, and it is therefore easy to explain why the feeling of the passing of time can persist even when the body is entirely still. We might think, then, that experience is relentlessly agentive: as long as we are conscious we are always either changing where our body is in space, changing the landscape of our mind, or changing where our attention is directed.

While I am sympathetic to this idea, I will not argue for it further here. This is because there is a second, more modest, response available to the challenge we are currently considering. Recall that the problem for approaches based on change perception was not to explain why it always seems as if time is passing but rather to explain how experience could have a dynamic flavour, even when we are not witnessing objects changing. We can say, therefore, that there are moments in which we are enjoy a feeling of time passing due to mental actions or shifts in attention, even when our bodies are entirely inactive, while also accepting that there are moments in which we do not experience ourselves as the source of any type of action and so do not involve a feeling of time passing. Indeed, if we think of those occasions about which we might say 'I lost track of time', they would seem to be cases in which we $d o$ not have a sense of our movements or thoughts as being brought about by ourselves. Consider moments at which one is thoroughly absorbed in some skilful activity, such as playing a musical instrument, or fully engrossed in a daydream. ${ }^{18}$ Each can be characterised not only as an occasion on which we lose track of time, but also as one in which we have little or no sense of causing our thoughts or movements: if we know the sonata well we do not have to think where to place our fingers on the piano keys, rather our movements are guided by a mixture of rote memory and immediate response to stimuli; if we are lost in a daydream we do not seem to actively change our mental landscape but instead one thought brings forth the next, which brings forth the one after that. ${ }^{19}$ If this is correct we can say that identifying our sense of instigating change with the feeling of time passing, not only avoids the problems of accounts based on perceiving change but a neat answer as to why our feeling of time passing varies depending on the situation.

For reasons that will become clear in a moment I want to take care in describing the character of these types of cases. In particular, we should be careful not to confuse not experiencing oneself as effecting change with experiencing oneself as not effecting change. Absorbed activity and daydreaming, I suggest, are cases of the former not the latter. In other words, whenever I do experience myself as an agent I experience myself as effecting change. Consider again Horgan's description of what agentive experience is not like. You do not experience parts of your body as "fortuitously moving just as you want them to move, or passively experiencing them as being caused by your own mental states" (2011, p. 79). If this were how our sense of agency was

\footnotetext{
${ }^{17}$ See Watzl (2017, ch. 11) for a discussion on shifting attention and agentive awareness.

${ }^{18}$ See Dorsch (2015) for a discussion of the role of agency, or lack thereof, in different types of daydreaming and mind-wandering.

${ }^{19}$ Losing track of time is considered one of the defining characteristics of a flow state (Nakamura \& Csikszentmihalyi 2014, p.90).
} 
we would indeed experience ourselves as subjects but not causes. But just as this is not an apt description for what it is like to act, neither is it an apt description of what it is like to be engrossed in an action or stream of thought. Daydreaming or playing the piano is not a case of 'stepping back' and observing a series of automatic thoughts or movements. Rather, when one is truly absorbed, the sense of agency evaporates.

\section{Having to act and believing in passage}

Experiencing oneself as an agent is to experience a particularly intimate form of change, which pervades all, or at least a large proportion of, the instants at which we are conscious. Here, I shall argue that, while not being a representation of a changing present, this type of experience invites us to believe that there is such a thing in much the same way that Hoerl says that a lack of temporal view pointedness invites a belief in the privileged present.

Section 4 showed that there is a contrast between spatial experience of objects and temporal experience of events. Our spatial experience makes manifest both why we are perceiving the objects we are perceiving and the way that they are perceived: I am seeing this ice cream in profile because I am viewing it from this spatial viewpoint. Temporal experience is not viewpointed in the same way and so does not make manifest why we are perceiving this event at this particular instant. In agentive experience we find analogs to both. In sensing myself as a generating my actions, the reason why my body is moving the way it is is made experientially manifest: I sense myself as the source of my licking, and as not taking up any of the other options that are available to me (dropping my ice cream, tightening my grip so as to crush it etc.). But what agentive experience does not make manifest, is why I invariably find myself as effecting change. It is this negative feature of agentive experience, I suggest, which provides a basis for the belief in a changing present.

As mentioned above, even if there are moments in which we do not experience ourselves as agents, such as in a daydream, whenever we do experience ourselves as agents, we always experience ourselves as doing something. That is, we never experience ourselves as agents who are not effecting change. ${ }^{20}$ Whatever the reason for our being in such a state, it is not revealed in experience: I do not sense myself as the cause of my having to act. If I did, it would seem to me as if I had the option to be entirely inactive: I would not only feel as if I could stop licking my ice cream at any instant, but also that, at any instant, I could put myself into a state in which I am not effecting change. As any insomniac will attest, we cannot choose to shut ourselves down in the way that we can a laptop, and neither do we experience ourselves as being able to do so. ${ }^{21}$

\footnotetext{
20 This point is somewhat similar to Sartre's idea that we are condemned to be free (1948/2007): we always find ourselves as having to make some choice. That is, to effect some sort of change.

${ }^{21}$ Of course it is possible to act in such a way as to facilitate an inactive state: we close our eyes in the hope that sleep will come, but this is not to choose to stop acting so much as to choose to act in a way which might stop you acting at some later point.
} 
The fact that inactivity never seems to be an option shows that we do not experience ourselves as the source of our being active. Neither does experience present our active state as being caused by something other than ourselves. Consider how some involuntary movements have what we might call felt causes. If you squirm when I poke you in the ribs you do not experience yourself as the source of your squirming, but neither is it a mystery to you as to why your body is moving like that: you experience the poking to be the cause of your squirming. Being in an active state, however, does not seem to have a felt cause. We do not experience ourselves as being prodded into action but are instead presented with the bare occurrence of our effecting change in a way similar to how Hoerl describes perception as presenting us with the bare occurrence of events. ${ }^{22}$ As we saw, Hoerl argues that this negative feature of temporal perception invites the belief that there is a privileged present moment. I want to suggest that, similarly, not experiencing the cause of our being active invites the belief that this present is changing.

We saw that on Hoerl's account, by not providing an answer as to why we are experiencing this event rather than any other, perception invites the idea that there must be some metaphysical fact independent of ourselves which explains this. Similarly, agentive experience does not present us with a reason as to why we are active, and so can be thought of as inviting the idea that there must instead be some fact independent of ourselves which accounts for this instead: if I am not causing it, and do not experience anything else as causing it, it must be something else. If this line of thinking is correct then the next step is to show that we believe this something else to be a changing present.

Here, my explanation is slightly different to Hoerl's. While his relies on an implicit comparison between what we perceive and what we remember or anticipate, mine relies on accounting for a feature which is ever present in agentive experience: the pervasive, intimate, and immanent experience of change that is feeling ourselves act. Every instant at which we catch ourselves doing, or thinking, or attending, is an experience of change, and while we have an explanation as to how this change unfolds -we sense ourselves as guiding it- we do not have an explanation as to why there is change at all. Whenever we perceive change we can ask why it is occurring: Why is the ice cream melting? And if the change is not experienced as something to do with us, we come to believe that it is due to some fact about the world. If I am not causing the ice cream to melt, something (or things) other than me must be responsible: some property of the ice cream itself, some feature of the environment, etc. Given that agentive change is there at every instant we experience ourselves as acting, this leads us to believe that it does not have a local, contingent cause, but a global one.

\footnotetext{
${ }^{22}$ While the question as to the actual cause of our being active is interesting, it is not something I need to address here. Any answer would most likely appeal to the fact that our brains are perpetually active systems. The patterns of neural activation which underlie our perceiving, thinking about, and responding to the world do not cease for as long as we are awake, and so it is unsurprising that we always find ourselves doing something. If we were aware of this neural churning as causing our activity, then, according to the argument I am making here, we would not come to believe that the present moment is changing. However, my proposal does not rely on experience withholding the correct answer, only that it provides no answer. Even if agentive experience were misleading and presented a cause for our being in an active state which was not the real cause, this would be sufficient, I suggest, to prevent it inviting belief in a changing present.
} 
That is, our having to act seems to require a metaphysical explanation: the change we experience must be a feature of reality itself. According to Hoerl, perceiving the bare occurrence of some event or other leads to the belief that the instant of perception is somehow special; on my account it is the bare occurrence of our own agentive restlessness which leads us to believe that that instant is in some special sort of flux. Experiencing the irresistible flow of our actions leads us to believe that we are being swept along by a changing present.

\section{Conclusions}

I have argued here that if we are looking for an aspect of experience which elicits the belief in the passage of time, then our sense of ourselves as sources of action is a promising candidate. The feeling of time passing is the feeling of acting, of effecting change. Unlike direct perceptual accounts, this approach is not vulnerable to worries regarding its veridicality or lack thereof, and, unlike accounts based on perceptions of ordinary change, provides a uncomplicated account of why the feeling of time passing persists even when we are not witnessing change occurring in the world around us. While the experience of generating change is not a representation of the present moment changing, there is a clear route from this type of experience to a belief in a changing present moment. The fact that whenever we experience ourselves, we experience ourselves as effecting change, coupled with the fact agentive experience does not make manifest to us why this is the case, provides an explanation as to how agentive experience invites a belief in a changing present.

Acknowledgements This research was funded by the Department of Philosophy "Piero Martinetti" of the University of Milan under the Project "Departments of Excellence 2018-2022" awarded by the Ministry of Education, University and Research (MIUR) and the project "Time and Emotion" (ID-35533) of the University of Milan. Support was also received from the project "Rethinking and communicating time (CHRONOS)", PID2019-108762GB-I00 of the Spanish Ministry of Science and Innovation. For feedback on previous versions of this material, thanks to all participants at the 'The First International Conference on Time' at Osaka City University in November 2019, and Giovanni Merlo's Time Reading group held online in November 2020. Thanks also to two anonymous referees for their extremely helpful comments, and my colleagues at the Centre for Philosophy of Time at the University of Milan, in particular Davide Bordini, Dave Ingram, Cristian Mariani, and Luca Marchetti. Special thanks to Giuliano Torrengo for his many detailed comments on many aspects of this paper, as well as Natalia Panchieri and Bryan O'Donovan, both of whom have helped me think more clearly about the issues that I write about here.

Open Access This article is licensed under a Creative Commons Attribution 4.0 International License, which permits use, sharing, adaptation, distribution and reproduction in any medium or format, as long as you give appropriate credit to the original author(s) and the source, provide a link to the Creative Commons licence, and indicate if changes were made. The images or other third party material in this article are included in the article's Creative Commons licence, unless indicated otherwise in a credit line to the material. If material is not included in the article's Creative Commons licence and your intended use is not permitted by statutory regulation or exceeds the permitted use, you will need to obtain permission directly from the copyright holder. To view a copy of this licence, visit http:/creativecommons.org/ licenses/by/4.0/. 


\section{References}

Armstrong, D. M. (2002). A materialist theory of the mind. Routledge

Arstila, V. (2018). Temporal experiences without the specious present. Australasian Journal of Philosophy, 96(2), 287-302

Balashov, Y. (2005). Times of Our Lives: Negotiating the Presence of Experience. American Philosophical Quarterly, 42(4), 295-309

Bayne, T. (2008). The phenomenology of agency. Philosophy Compass , 3(1), 182-202

Borges, J. L. (1962). The secret miracle. Labyrinths: Selected stories and Other Writings, 88-94

Callender, C. (2017). What makes time special?. Oxford University Press

Cameron, R. P. (2015). The moving spotlight: An essay on time and ontology. Oxford University Press Oxford

Chalmers, D.(2004). The representational character of experience. In: A. Bardon (Ed.), The Future of the Philosophy of Time (pp. 153-181). New York: Clarendon Press

Correia, F., \& Rosenkranz, S. (2018). Nothing to come: A defence of the growing block theory of time (Vol.395). Springer

Crane, T. (2009). Intentionalism In: McLaughlin,B., Beckermann, A., \& Walter, S. (Eds.). (2009). The Oxford handbook of philosophy of mind. Oxford University Press

Dainton, B.(2012). Time and Temporal Experience. In: A. Bardon (Ed.), The Future of the Philosophy of Time. New York: Routledge

Davies, P. (1995). About time: Einstein's unfinished revolution. Penguin

Deng, N. (2013). Fine's McTaggart, temporal passage, and the A versus B-debate. Ratio, 26(1), 19-34

Dorsch, F. (2015). Focused daydreaming and mind-wandering. Review of Philosophy and Psychology, 6(4), 791-813

Farr, M. (2020). Explaining temporal qualia. European Journal for Philosophy of Science, 10(1), 1-24

Hoerl, C. (2014). Do we (seem to) perceive passage?. Philosophical Explorations, 17(2),188-202

Hoerl, C. (2018a). Experience and time: transparency and presence. Ergo, an Open Access Journal of Philosophy, 5

Hoerl, C. (2018b). Transparency, Time, and Perspective: Reply to Richardson, Carter and Lee. https:// philosophyofbrains.com/wp-content/uploads/2018/09/Brains-blog-reply_CH.pdf

Horgan, T. (2011). The phenomenology of agency and freedom: Lessons from introspection and lessons from its limits. Humana Mente, 15, 77-97

Ingram, D. (2018). Thisness Presentism: An Essay on Time, Truth, and Ontology. Routledge

Hohwy, J., Paton, B., \& Palmer, C. (2015). Distrusting the present. Phenomenology and the Cognitive Sciences, 15(3), 315-335. https://doi.org/10.1007/s11097-015-9439-6

Ismael, J.(2012). Decision and the open future In: A. Bardon (Ed.), The Future of the Philosophy of Time. New York: Routledge

Kolers, P. A., \& von Grünau, M. (1976). Shape and Colour in Apparent Motion. Vision Research 16/4, (pp. 329-35)

Kriegel, U. (2015a). Experiencing the present. Analysis, 75(3), 407-413

Kriegel, U. (2015b). The varieties of consciousness. Oxford University Press

Latham, A. J., Miller, K., \& Norton, J. (2020). Do the folk represent time as essentially dynamical?. Inquiry, 1-32

Latham, A. J., Miller, K., \& Norton, J. (2021). Is our naïve theory of time dynamical? Synthese, 198(5), $4251-4271$

Lee, G. (2014). Extensionalism, atomism, and continuity. In: Oaklander, L.N. (Ed.), Debates in the Metaphysics of Time, (pp. 149-173)

Leininger, L. (2013). On Mellor and the future direction of time. Analysis, 74(1), 1-9

Miller, K. (2019). Does it really seem to us as though time passes?. In: The Illusions of Time (pp. 17-33). Palgrave Macmillan, Cham

Miller, K., Holcombe, A., \& Latham, A. J. (2020). Temporal phenomenology: phenomenological illusion versus cognitive error. Synthese, 197(2), 751-771

Mozersky, M. J. (2015). Time, Language, and Ontology: The World from the B-Theoretic Perspective. Oxford, UK: Oxford University Press

Mylopoulos, M., \& Shepherd, J.(2020). The experience of agency. In: U. Kriegel (Ed.), The Oxford Handbook of the Philosophy of Consciousness (pp. 164-168). Oxford University Press 
Nakamura, J., \& Csikszentmihalyi, M. (2014). The concept of flow. In: Flow and the foundations of positive psychology (pp. 239-263). Springer, Dordrecht

Nichols, S., \& Stich, S. P. (2003). Mindreading: an integrated account of pretence, self-awareness, and understanding other minds. Clarendon Press/Oxford University Press

Nida-Rümelin, M. (2018). Freedom and the Phenomenology of Agency. Erkenntnis, 83(1), 61-87

O'Shaughnessy, B. (2000). Consciousness and the World. Oxford: Oxford University Press

Paul, L. A. (2010). Temporal experience. The Journal of Philosophy, 107 (7), 333-359

Phillips, I. (2013). October). XII-Perceiving the passing of time. In: Proceedings of the Aristotelian Society (Vol. 113, No.3_pt_3, pp. 225-252). Oxford, UK:Oxford University Press

Phillips, I. (2014). The temporal structure of experience. In: Subjective time: The philosophy, psychology, and neuroscience of temporality, 139-158

Prosser, S. (2013). Passage and perception. Noûs, 47(1), 69-84

Prosser, S. (2016). Experiencing time. Oxford University Press

Sartre, J. P. (1948/2007). Existentialism is a humanism. (C. Macomber, Trans.). Yale University Press

Shardlow, J., Lee, R., Hoerl, C., McCormack, T., Burns, P., \& Fernandes, A. S. (2021). Exploring people's beliefs about the experience of time. Synthese, 198(11), 10709-10731

Shoemaker, S. (1994). Self-knowledge and "inner sense." Philosophy and Phenomenological Research, $54,249-314$

Skow, B. (2015). Objective becoming. Oxford University Press,USA

Strawson, G. (2010). Freedom and Belief (Revised Edition). Oxford: Oxford University Press

Torrengo, G. (2017). Feeling the passing of time. Journal of Philosophy, 114(4), 165-188

Watzl, S. (2017). Structuring mind: The nature of attention and how it shapes consciousness. Oxford University Press

Wright, C.(2000). Self-knowledge: the Wittgensteinian legacy. In: C. Wright, B. C. Smith, \& C. Macdonald (Eds.), Knowing Our Own Minds. Oxford: Oxford University Press

Publisher's Note Springer Nature remains neutral with regard to jurisdictional claims in published maps and institutional affiliations. 